\title{
Liver (HepG2) cells as a model for studying the physiological effects of iron depletion
}

\author{
L. Mossa ${ }^{1,2}$, L. Gambling ${ }^{1}$, R. Scott ${ }^{2}$ and H. J. McArdle ${ }^{1}$ \\ ${ }^{1}$ The Rowett Institute of Nutrition and Health, University of Aberdeen, Greenburn Road, Bucksburn, Aberdeen AB21 9SB, \\ UK and ${ }^{2}$ School of Medical Sciences, Institute of Medical Sciences, University of Aberdeen, Foresterhill, \\ Aberde 25 2ZD, UK
}

Iron $(\mathrm{Fe})$ deficiency during pregnancy has serious health consequences for both the mother and her developing fetus. In rats, the pups born to Fe-deficient mothers are smaller, with changes in liver and heart size, and, as adults, the offspring have increased blood pressure and can develop obesity ${ }^{(1)}$. Why these changes occur is not clear. One possible hypothesis is that Fe deficiency changes the cell membrane, altering their lipid profile and changing their electrophysiological properties. This abstract presents data testing this hypothesis. Human liver hepatoma cell line (HepG2) cells were grown to $80 \%$ confluence and incubated with the Fe chelating agent desferrioxamine (DFO) at different concentrations and for different times. Cell proliferation and survival were determined by cell counting, DNA content and lactate dehydrogenase assay. Whole cell patch clamp recording was used to measure holding current at $-70 \mathrm{mV}$, to generate currentvoltage relationships and record whole current responses to a pore forming marine sponge toxin (polymeric alkyl pyridinium salt, Poly$\left.\mathrm{APS}^{(2)}\right)$. DFO generates a functional, rather than an actual, Fe deficiency, so that measuring the Fe content of the cell does not reflect the Fe status. Instead, we measured mRNA levels for transferrin receptor. Exposing HepG2 cell cultures to $20 \mu \mathrm{M}$ DFO for $18 \mathrm{~h}$ resulted in no significant loss of cell number, while $50 \mu \mathrm{M}$ DFO significantly reduced cell survival. Therefore, $20 \mu \mathrm{M}$ DFO for $18 \mathrm{~h}$ was used for the electrophysiological experiments. HepG2 cells had linear current-voltage relationships between -130 and $+60 \mathrm{mV}$. Exposure of HepG2 cells for $18 \mathrm{~h}$ to $20 \mu \mathrm{M}$ DFO reduced input resistance as reflected by an increase in holding current and an increase in slope conductance. This was not reversed by a cocktail of $\mathrm{Ba}^{2+}(5 \mathrm{~mm})$ and quinine $(100 \mu \mathrm{M})$, suggesting no change in $\mathrm{K}$ channel protein expression. Fe depletion may result in a change in lipid constituents of the cell membrane rather than a change in $\mathrm{K}^{+}$channel expression. However, any change in membrane lipids was not sufficient to alter the sensitivity of cells to pore formation by $10 \mu \mathrm{g} / \mathrm{ml}$ Poly-APS. Further work is needed to identify why the properties have changed, but these observations may explain, at least in part, why Fe deficiency in pregnancy results in long-term programming changes in the offspring.

The authors thank RERAD, EARNEST and NuGO for support.

1. Gambling L, Andersen HS, Czopek A et al (2004). J Physiol 561, 195-203.

2. McClelland D, Evans RM, Abidin I et al (2003) Br J Pharmacol 139, 1399-1408. 